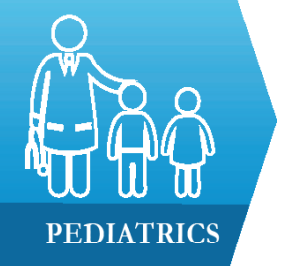

1) Mother and Child Department, Iuliu Hatieganu University of Medicine and Pharmacy, Cluj-Napoca, Romania

2) $3^{\text {rd }}$ Pediatric Department, Clinical Emergency Hospital for Children, ClujNapoca, Romania

3) Radiology Department, Clinical Emergency Hospital for Children, ClujNapoca, Romania
DOI: $10.15386 / \mathrm{mpr}-1894$

Manuscript received: 04.09.2020

Received in revised form: 23.09 .2020

Accepted: 12.10.2020

Address for correspondence:

daniellapop@yahoo.com

This work is licensed under a Creative Commons Attribution-NonCommercialNoDerivatives 4.0 International License

\section{Changes in the parameters of the rectoanal inhibitory reflex in children with functional constipation and large rectum}

Daniela Pop ${ }^{1}$, Simona Tătar ${ }^{2}$, Otilia Fufezan ${ }^{3}$, Dorin Farcău ${ }^{1,2}$

\begin{abstract}
Background. Abdominal ultrasound and anorectal manometry are part of the investigations used to assess children with functional constipation. This study aimed at assessing the changes in the characteristics of the rectoanal inhibitory reflex (RAIR) in children with functional constipation and correlating them with the dimensions of the rectum, measured by abdominal ultrasound. A secondary objective was to compare the rectum size in children with and without constipation.

Method. We retrospectively reviewed the clinical data and investigations results of 51 children (mean age \pm standard deviation $(\mathrm{SD})=5.8 \pm 3.5$ years) with functional constipation who came to our clinic between January 2013 and February 2020. The assessment of these patients included both the assessment of the transverse diameter of the rectal ampulla by abdominal ultrasound and anorectal manometry. The studied parameters of RAIR were: the minimal volume of air necessary to induce RAIR, in all the patients with functional constipation, and in 20 of them, relaxation time, latency and relaxation percentage. A control group was formed of 27 children (mean age \pm SD $=5.1 \pm 4$ years) without digestive diseases and with normal intestinal transit, who were assessed by abdominal ultrasound.

Results. The mean value \pm SD of the volume of air necessary to induce RAIR was $21.9 \pm 12.1 \mathrm{~cm} 3$ air. There was no correlation between the rectum transverse diameter and the minimal air volume that triggered RAIR $(r=-0.01, p=0.94)$. The mean value \pm SD of the transverse diameter of the rectum in patients with functional constipation was $39 \pm 14 \mathrm{~mm}$, and in children without constipation $26 \pm 6 \mathrm{~mm}(\mathrm{p}<0.05)$. The mean duration of the symptoms in children with functional constipation was 2.8 years.

Conclusions. There were no correlations between the volume of air that induced the RAIR and the transverse diameter of the rectum in children with functional constipation. The transverse diameter of the rectum was increased in children with long-term functional constipation.
\end{abstract}

Keywords: functional constipation, abdominal ultrasound, rectoanal inhibitory reflex, children

\section{Background}

Chronic constipation in children is a frequent reason for presenting to the primary care physician, pediatrician, or pediatric gastroenterologist. Often, an organic cause is not found, and children are diagnosed with functional constipation [1]. Frequently in children, functional constipation is caused by the retention of feces in the rectum, which leads to enlargement and, progressively, to an alteration of the rectal sensitivity parameters [1,2]. The consequences of this disorder that has no anatomic, histopathological, inflammatory, or biochemical explanation, can be serious, especially if the evolution is prolonged (sometimes for years), neglected, or not responsive to conventional treatment, leading to anal fissures, hemorrhoids, or fecal incontinence.

The diagnosis of functional constipation was based on Rome III $[3,4]$ and Rome IV $[5,6]$ criteria. The child must 
have at least two of the following symptoms, for at least one month: two or fewer defecations per week, excessive stool retention, painful or hard bowel movements, retentive posturing, large fecal mass in the rectum, large diameter stools that can obstruct the toilet, and at least 1 episode of fecal incontinence, for toilet trained children under 4 years and for children exceeding than 4 years of age. Other diseases that might explain the symptoms must be excluded [3-6].

Abdominal ultrasound is considered, by some authors, useful in the assessment of patients with functional constipation. It helps detect a fecal mass impacted in the rectum and in the assessment of the rectum transverse diameter, larger in patients with constipation than in those with normal bowel movement $[2,7,8]$. Nevertheless, the investigation is not generally accepted because the studies investigated small groups of patients, and the rectum size depends on the moment of defecation [9].

The main indication for performing anorectal manometry is related to the investigation of patients with possible Hirschsprung's disease, the absence of the rectoanal inhibitory reflex (RAIR) being an important clue in this disorder $[2,10]$. Hirschsprung's disease affects the development of the enteric nervous system. It is characterized by aganglionosis of the myenteric and submucosal plexus, starting with the anorectal region and extending on a variable length in the rest of the colon and intestine [11]. The diagnosis is often established before the child is one year old. In less severe forms, the diagnosis might be established later in life.

Anorectal manometry is also indicated in patients with functional constipation resistant to conventional treatment, fecal incontinence, and assessment of the anal canal and rectum function in patients with anorectal malformations before and after the surgical procedure [11,12].

RAIR is the relaxation of the internal anal sphincter in response to the rectum distention by accumulation of feces. This reflex is triggered during anorectal manometry by inflation of air in the intrarectal balloon, thus mimicking the presence of the feces [11]. It is considered that this reflex is present when the pressure of the anal sphincter decreases by at least $5 \mathrm{mmHg}$ or by $15 \%$ of the basal value, after a short initial increase of the pressure [11].

Our objectives were to investigate the changes of the parameters that characterize RAIR in children with functional constipation (minimal volume used to induce RAIR, relaxation time, latency, and relaxation percent) and correlate these findings with the dimensions of the rectum as measured by abdominal ultrasonography. A secondary aim was to compare the transverse diameter of the rectum in children with functional constipation and children with normal intestinal transit.

\section{Material and method}

We retrospectively analyzed the clinical data and the investigation results of 51 children, diagnosed with functional constipation, aged between 4 months and 14 years (mean age \pm standard deviation $(\mathrm{SD})=5.8 \pm 3.5$ years (median $=5.7$ years)), 32 boys $(62 \%)$. These were patients assessed between January 2013 and February 2020 using both measuring the transverse diameter of the rectum by abdominal ultrasonography and anorectal manometry. The diagnosis of functional constipation was based on the Rome III $[8,9]$ and Rome IV [10,11] criteria, after excluding other causes of organic constipation.

We excluded patients with organic causes of constipation (Hirschsprung's disease, celiac disease, hypothyroidism, neurological diseases, etc) and children with anorectal malformations from the study. We also excluded from the study patients who did not have both investigations performed or the results were not interpretable.

A control group was formed of 27 children without digestive disorders and with normal intestinal transit, aged between 4 months and 13 years (mean age $\pm \mathrm{SD}=5.1 \pm 4$ years, median $=3.8$ years), 17 boys $(63 \%)$. These children were assessed by abdominal ultrasound for other indications, and the rectum's transverse diameter was measured.

\section{Abdominal ultrasound}

The measurement of the rectum size was performed in all patients before they had the enema used for emptying the rectum before the anorectal manometry. The device used for the abdominal ultrasound was a Toshiba Xario 200, with a convex transducer of 4-6 MHz and a linear transducer of 7-14 MHz. We performed a transverse scan of the pelvic region, posterior to the bladder, and the image of the rectal ampulla was found. We chose the section in which the rectal ampulla was largest, and the transverse diameter of the rectum was measured, using the convex transducer for older children and the linear for younger children.

\section{Anorectal manometry}

Anorectal manometry was performed using a conventional method, with water perfused catheters. The device used for anorectal manometry was a Mui Scientific Model PIP 48220S5. The four channels of the catheter open through holes radially placed at the distal end of the catheter, where a balloon is also found. The catheter and the balloon are introduced in the rectum. Then, by slowly withdrawing it, the holes of the water-perfused channels are placed at high-pressure zone level, corresponding to the internal anal sphincter. After the stabilization of the anal sphincter basal pressure, we rapidly introduced higher and higher volumes of air in the intrarectal balloon, attempting to trigger RAIR. The examination was started by introducing $10 \mathrm{~cm}^{3}$ air, then 20,30 , and, where it was needed, $40,50 \mathrm{~cm}^{3}$ air.

For every patient, we recorded the minimal volume of air that triggered RAIR. Artifacts might occur during anorectal manometry due to the voluntary contraction of the external anal sphincter or to the intrarectal displacement of the catheter holes from the anal sphincter, because of the traction of the balloon inflated with air, leading to a false decrease of pressure. In order to obtain accurate results, we made three determinations for each patient, for the minimal air volume that triggered RAIR.

- For 20 of the patients with constipation, we 
recorded the relaxation time, latency, and relaxation percentage of the anal sphincter. Relaxation time is the period between the initial decrease of the anal sphincter pressure and the moment of maximum relaxation. It is measured in seconds.

- Latency is the time, measured in seconds, between the distention of the balloon and relaxation of the anal sphincter.

- Relaxation percentage is the difference between the pressure of the anal sphincter before the relaxation and the pressure at the maximum relaxation point.

Parents signed an informed consent before the investigations were performed.

\section{Statistical analysis}

We used the T Student and Mann Whitney tests for the statistical analysis of data. For the correlation of some parameters, we used the Pearson correlation coefficient. Statistically significant results were considered for $\mathrm{p}<0.05$.

\section{Results}

In all the constipated patients, RAIR was present. The volume of air needed to induce this reflex and the number of patients with the corresponding amount are listed in table I. The mean value \pm SD of this volume of air was $21.9 \pm 12.1$ $\mathrm{cm}^{3}$ air (median $=20 \mathrm{~cm}^{3}$ air) in patients with functional constipation. In 7 patients (14\%), the minimal volume of air necessary to induce RAIR was higher than $40 \mathrm{~cm}^{3}$ air (tracings of some recordings are illustrated in Figures 1 and 2).

Table I. Minimal volume of air that triggered RAIR in patients with constipation.

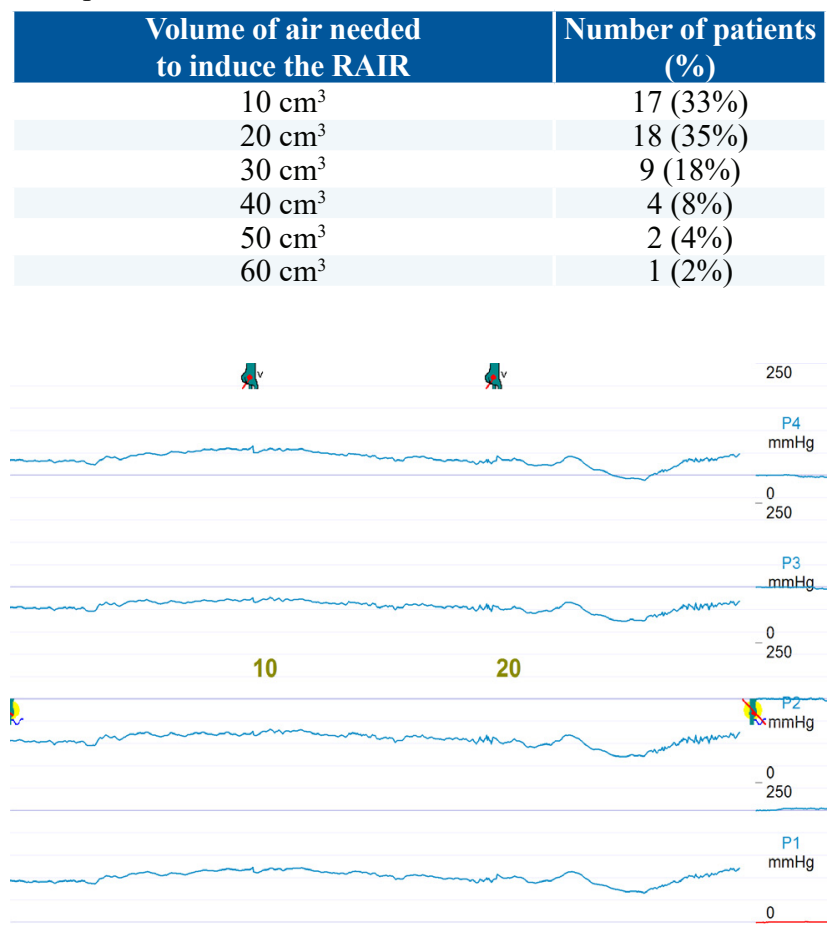

Figure 1. RAIR triggered by inflating $20 \mathrm{~cm}^{3}$ air in the intrarectal balloon.

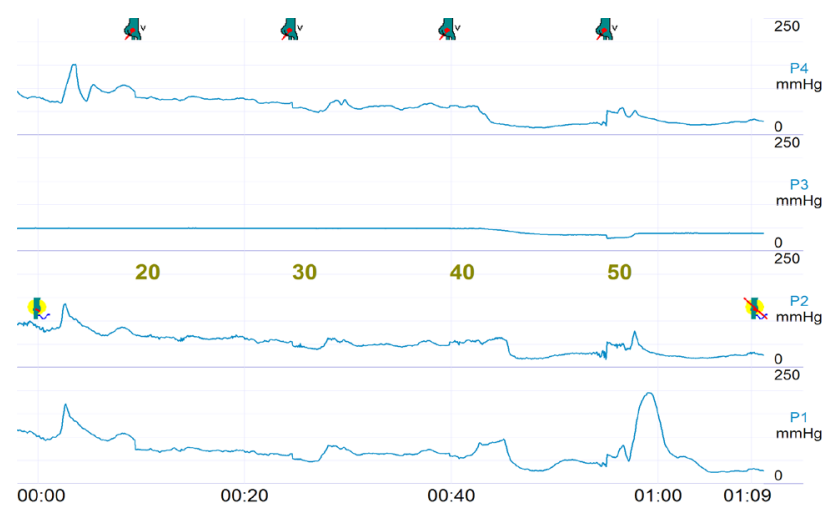

Figure 2. RAIR triggered by inflating 40 and $50 \mathrm{~cm}^{3}$ air in the intrarectal balloon.

The length of symptoms in patients with functional constipation was between 2 months and 10 years (mean value $\pm \mathrm{SD}=2.8 \pm 2.6$ years, median $=2.1$ years). The value of the minimal amount of air inflated in the intrarectal balloon to trigger RAIR was not correlated with the length of symptoms $(r=-0.05, p=0.72)$.

The mean value \pm SD of the rectal diameter in patients with functional constipation was $39 \pm 14 \mathrm{~mm}$ (median $=40$ $\mathrm{mm}$ ). There was no correlation between the rectum transverse diameter, measured by abdominal ultrasound, and the volume of air necessary to induce RAIR ( $\mathrm{r}=-0.01$, $\mathrm{p}=0.94)$.

In 20 patients with functional constipation, we recorded 3 more parameters of RAIR (calculated automatically by the software of the device): relaxation time, latency, and relaxation percentage. The results are shown in table II.

Table II. RAIR parameters and characteristics of the patients with functional constipation.
Number of patients

Age range (mean value $\pm \mathrm{SD}$ )

Transverse diameter of the rectum (mean value $\pm \mathrm{SD}$ )

Minimal volume of air that triggered RAIR

Relaxation time

Latency

Relaxation percent $\mathrm{n}=\mathbf{2 0}$

9 months -13 years ( $5 \pm 3.7$ years)

$34.6 \pm 9.3 \mathrm{~mm}$

$25.5 \pm 12.7 \mathrm{~cm}^{3}$ air

$6.5 \pm 3$ seconds

$5.5 \pm 3$ seconds $58 \pm 20 \%$
We found a mild correlation between the transverse diameter of the rectum and the relaxation time in patients with functional constipation $(\mathrm{r}=0.23 ; \mathrm{p}>0.05)$, but the results were not statistically significant. There were no correlations between the transverse diameter of the rectum and latency $(\mathrm{r}=-0.09 ; \mathrm{p}>0.05)$ or relaxation percentage of the anal sphincter $(\mathrm{r}=-0.01, \mathrm{p}>0.05)$. 
Table III. Normal values of the minimal volume of air that triggered RAIR [7].

\begin{tabular}{l|c|c|c} 
Authors & $\begin{array}{c}\text { Number of healthy } \\
\text { children }\end{array}$ & Age & $\begin{array}{c}\text { Minimal volume of air that induced RAIR } \\
\text { (cm }^{\mathbf{3}} \mathbf{a i r}^{-}\end{array}$ \\
\hline Benninga et al. [17] & 13 & $8-16$ years & $18 \pm 10$ \\
Hyman et al. [18] & 16 & $>5$ years & $11 \pm 5$ \\
Kumar et al. [16] & 30 & $1-16$ months & $14 \pm 10$ \\
Kumar et al. [16] & 30 & 18 months-12 years & $24 \pm 12$
\end{tabular}

There was no correlation between the minimal amount of air needed to induce RAIR and relaxation time $(\mathrm{r}=0.09 ; \mathrm{p}>0.05)$. There was a mild, but not statistically significant correlation with latency $(\mathrm{r}=0.29 ; \mathrm{p}>0.05)$ and relaxation percentage $(r=0.32 ; \mathrm{p}>0.05)$.

The control group was aged-matched with the children with functional constipation $(p>0.05)$. The mean value \pm SD of the rectal diameter in children without constipation was $26 \pm 6 \mathrm{~mm}$ (median $25 \mathrm{~mm}$ ). The difference with the values recorded in children with functional constipation was statistically significant $(\mathrm{p}<0.05)$.

There were $37 / 51$ (72\%) patients with functional constipation, with the diameter of the rectum exceeding 30 $\mathrm{mm}$.

Symptoms with significant length in patients with functional constipation was correlated with the diameter of the rectum $(\mathrm{r}=0.409, \mathrm{p}=0.002)$ (Figure 3$)$.

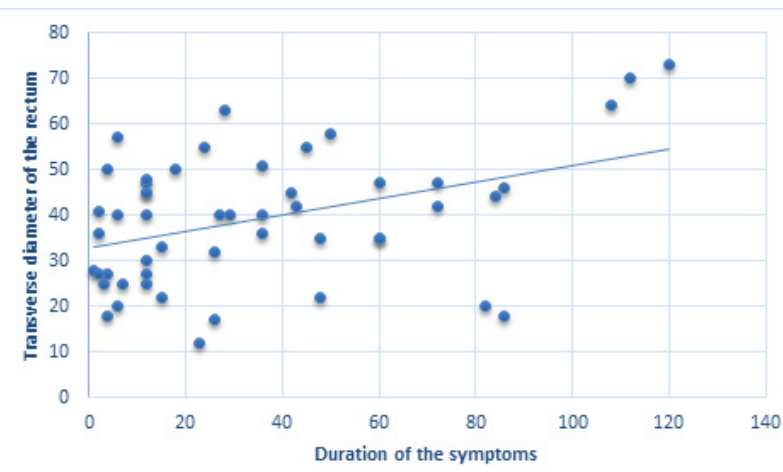

Figure 3. Correlation between length of symptoms (months) and the transverse diameter of the rectum $(\mathrm{mm})$.

\section{Discussion}

In most of the studies, the results regarding RAIR are limited to mentioning whether it is present or not, and if it is present, authors mention only what was the volume of air that induced it. It is considered that in patients with large rectum, regardless of the cause of the distension, RAIR is absent, or large volumes of air are needed to document it (50-80 $\mathrm{cm}^{3}$ air) [13]. The length and amplitude of the relaxation increase with the amount of air introduced in the intrarectal balloon $[14,15]$.

In our patients, there was no correlation between the rectum diameter and the volume of air for RAIR, but the mean value of the volume of air was higher than most of the normal values found in other studies. Kumar et al. [16] reported similar values in healthy children aged between 18 months and 12 years, as those found by us in children with functional constipation. Some of these normal values are shown in table III.

Morera et al. [19] studied the parameters of RAIR in patients with sacral agenesia (partial and total), which presented constipation and/or fecal incontinence and compared data with those recorded in patients with polyposis syndromes. Regarding the values of latency, these did not differ in the study groups, but comparing them with values found in children with functional constipation in our study, the mean value $\pm \mathrm{SD}$ of $5.5 \pm 3$ seconds recorded by us was much higher. Sangwan et al. [20] found similar latency values in adult patients with constipation, fecal incontinence, and normal controls in the proximal anal canal, but significantly higher values in the distal part in patients with fecal incontinence.

Studies in children found a lower amplitude of RAIR in patients with constipation, both with or without fecal incontinence, which persisted even after 3 years of treatment [21]. The presumed cause of the constipation was the inability of the internal anal sphincter to relax after the distension of the rectum [21]. A similar relaxation percentage of RAIR was found in adults with constipation by Netinho et al. [22] (54.1\%; 58\% was the result in our patients), but lower values than those recorded in patients with multiple sclerosis or spinal traumas [23]. Studies in adult patients showed and asymmetry of RAIR along the anal canal, with a progressive reduction of the amplitude from the proximal to the distal part [24,25], an observation also confirmed with high-resolution manometry [14].

The ESPGHAN and NASPGHAN guideline regarding the management of children with functional constipation does not recommend the use of abdominal ultrasound and measurement of the rectal diameter in diagnosing the disease [12]. Nevertheless, it brings valuable data regarding the impacted feces in the rectum, especially in children where a digital rectal examination is difficult and unpleasant. Some studies assessed this method's usefulness, but data was not enough to establish normal values of the rectum transverse diameter in similar conditions of measuring the rectal ampulla [26-30]. Our study compared the rectal transverse diameter of children with functional constipation with that of a group of 
children of comparable age without constipation. We found significantly higher values in children with constipation, as it was shown in other previous studies [8,26-28]. There was a mild correlation between the long duration of the symptoms and the large rectum transverse diameter in our group of patients with functional constipation.

The study brings results regarding possible consequences of the persistence of functional constipation on RAIR and size of the rectum. Changes in the structure of the rectum could lead to impaired function, and more specifically, this could affect a component involved in maintaining fecal continence. There are few studies in children evaluating RAIR parameters.

The limits of the study are given especially by the small number of patients included, and the small number of patients in which the parameters of RAIR (relaxation time, latency, and relaxation percentage) were recorded. We did not take the moment of defecation into consideration in evaluating the rectum diameter. The recovery time and total length of RAIR were not measured. We compared some of the parameters of the RAIR with results from studies in adults. Due to ethical reasons, there was no control group of children assessed with both abdominal ultrasound and anorectal manometry, which would have allowed a more objective comparison of the results.

Changes in RAIR in patients with functional constipation should be assessed in prospective studies. Patients should be assessed in similar conditions to allow an objective comparison of the results. Finding significant changes of RAIR features could be substantial. The question is whether these changes are the consequence of extended length of symptoms, large size of the rectum, or caused by abnormalities of the extrinsic innervations or of the enteric nervous system. This could explain the long-term symptoms in some patients with refractory constipation and fecal incontinence [31,32].

\section{Conclusions}

There were no correlations between a large transverse diameter of the rectum and a higher volume of air used to trigger RAIR in patients with functional constipation. In children with functional constipation, the large diameter of the rectum had a mild correlation, but not significant, with the longer relaxation time of the anal sphincter. The transverse diameter of the rectum was larger in children with functional constipation in correlation with the extended duration of the symptoms.

\section{References}

1. Paul SP, Broad SR, Spray C. Idiopathic constipation in children clinical practice guidelines. Arch Dis Child Educ Pract Ed. 2016;101:65-69.

2. Tambucci R, Quitadamo P, Thapar N, Zenzeri L, Caldaro T, Staiano A, et al. Diagnostic tests in pediatric constipation. J
Pediatr Gastroenterol Nutr. 2018;66:e89-e98.

3. Hyman PE, MillaPJ, Benninga MA, Davidson GP, FleisherDF, Taminiau J. Childhood functional gastrointestinal disorders: neonate/toddler. Gastroenterology. 2006;130:1519-1526.

4. Rasquin A, Di Lorenzo C, Forbes D, Guiraldes E, Hyams JS, Staiano A, van Tilburg Aet al. Childhood functional gastrointestinal disorders: child/adolescent. Gastroenterology. 2006;130:1527-1537.

5. Benninga MA, Faure C, Hyman PE, St James Roberts I, Schechter NL et al. Childhood Functional Gastrointestinal Disorders: Neonate/Toddler . Gastroenterology. 2016;S00165085(16)00182-7.

6. Hyams JS, Di Lorenzo C, Saps M, Shulman RJ, Staiano A, van Tilburg A. Childhood functional gastrointestinal disorders: child/adolescent. Gastroenterology. 2016;150:1456-1468.

7. Berger MY, Tabbers MM, Kurver MJ, Boluyt N, Benninga MA. Value of abdominal radiography, colonic transit time, and rectal ultrasound scanning in the diagnosis of idiopathic constipation in children: a systematic review. J Pediatr. 2012;161:44-50.e1-2.

8. Hatori R, Tomomasa T, Ishige T, Tatsuki M, Arakawa H. Fecal retention in childhood: Evaluation on ultrasonography. Pediatr Int. 2017;59:462-466.

9. Modin L, Dalby K, WalstedAM, Jakobsen M. Transabdominal ultrasound measurement of rectal diameter is dependent on time of defecation in constipated children. J Paediatr Child Health. 2015;51:875-880.

10. Rodriguez L, Sood M, Di Lorenzo C, Saps M. An ANMSNASPGHAN consensus document on anorectal and colonic manometry in children. Neurogastroenterol Motil. 2017;29. doi: $10.1111 / \mathrm{nmo} .12944$.

11. Le-Carlson M, Berquist W. Anorectal manometry In Faure C, Di Lorenzo C, Thapar N (eds.) Pediatric Neurogastroenterology-Gastrointestinal motility and functional disorders in children. 2013, Humana Press, p. 119-128.

12. Tabbers MM, DiLorenzo C, Berger MY, Faure C, Langendam MW, Nurko S, et al. Evaluation and treatment of functional constipation in infants and children: evidencebased recommendations from ESPGHAN and NASPGHAN. J Pediatr Gastroenterol Nutr. 2014;58:258-274.

13. Pfeifer J, Oliveira L. Anorectal Manometry and the Rectoanal Inhibitory Reflex. In: Wexner SD, Duthie GS (eds) Constipation. Springer, London. 2006, p. 71-83.

14. Cheeney G, Nguyen M, Valestin J, Rao SS. Topographic and manometric characterization of the recto-anal inhibitory reflex. Neurogastroenterol Motil. 2012;24:e147-e154.

15. Remes-Troche JM, De-Ocampo S, Valestin J, Rao SS. Rectoanal reflexes and sensorimotor response in rectal hyposensitivity. Dis Colon Rectum. 2010;53:1047-1054.

16. Kumar S, Ramadan S, Gupta V, Helmy S, Atta I, Alkholy A. Manometric tests of anorectal function in 90 healthy children: a clinical study from Kuwait. J Pediatr Surg. 2009;44:17861790.

17. Benninga MA, Wijers OB, van der Hoeven CW, Taminiau JA, Klopper PJ, Tytgat GN, et al. Manometry, profilometry, and endosonography: normal physiology and anatomy of the 
anal canal in healthy children. J Pediatr Gastroenterol Nutr. 1994; 18:68-77.

18. Di Lorenzo C. Constipation in Hyman PE, Di Lorenzo C (eds.). Pediatric gastrointestinal motility disorders. $1^{\text {st }}$ ed. New York: Academy Professional Information Services, Inc. 1994; p. 129-143.

19. Morera C, Nurko S. Rectal manometry in patients with isolated sacral agenesis. J Pediatr Gastroenterol Nutr. 2003;37:47-52.

20. Sangwan YP, Coller JA, Schoetz DJ Jr, Murray JJ, Roberts PL. Latency measurement of rectoanal reflexes. Dis Colon Rectum. 1995;38:1281-1285.

21. Loening-Baucke VA. Abnormal rectoanal function in children recovered from chronic constipation and encopresis. Gastroenterology. 1984;87:1299-1304.

22. Netinho JG, Ayrizono Mde L, Coy CS, Fagundes JJ, Góes JR. Amplitude and recovery velocity of relaxation induced by rectoanal inhibitory reflex and its importance for obstructive evacuation. Arq Gastroenterol. 2005;42:19-23.

23. Thiruppathy K, Roy A, Preziosi G, Pannicker J, Emmanuel A. Morphological abnormalities of the recto-anal inhibitory reflex reflects symptom pattern in neurogenic bowel. Dig Dis Sci. 2012;57:1908-1914.

24. Williamson JL, Nelson RL, Orsay C, Pearl RK, Abcarian $\mathrm{H}$. A comparison of simultaneous longitudinal and radial recordings of anal canal pressures. Dis Colon Rectum. 1990;33:201-206.

25. Goes RN, Simons AJ, Masri L, Beart RW Jr. Gradient of pressure and time between proximal anal canal and high- pressure zone during internal anal sphincter relaxation. Its role in the fecal continence mechanism. Dis Colon Rectum. 1995;38:1043-1046.

26. Joensson IM, Siggaard C, Rittig S, Hagstroem S, Djurhuus JC. Transabdominal ultrasound of rectum as a diagnostic tool in childhood constipation. J Urol. 2008;179:1997-2002.

27. Bijoś A, Czerwionka-Szaflarska M, Mazur A, Romañczuk W. The usefulness of ultrasound examination of the bowel as a method of assessment of functional chronic constipation in children. Pediatr Radiol. 2007;37:1247-1252.

28. Singh SJ, Gibbons NJ, Vincent MV, Sithole J, Nwokoma NJ, Alagarswami KV. Use of pelvic ultrasound in the diagnosis of megarectum in children with constipation. J Pediatr Surg. 2005;40:1941-1944.

29. Klijn AJ, Asselman M, Vijverberg MA, Dik P, de Jong TP. The diameter of the rectum on ultrasonography as a diagnostic tool for constipation in children with dysfunctional voiding. J Urol. 2004;172(5 Pt 1):1986-1988.

30. Doniger SJ, Dessie A, Latronica C. Measuring the Transrectal Diameter on Point-of-Care Ultrasound to Diagnose Constipation in Children. Pediatr Emerg Care. 2018;34:154159.

31. Xu X, Pasricha PJ, Sallam HS, Ma L, Chen JD. Clinical significance of quantitative assessment of rectoanal inhibitory reflex (RAIR) in patients with constipation. J Clin Gastroenterol. 2008;42:692-698.

32. Kaur G, Gardiner A, Duthie GS. Rectoanal reflex parameters in incontinence and constipation. Dis Colon Rectum. 2002;45:928-933. 